\title{
AVALIAÇÃO DA SOLDA MAG UTILIZANDO ARAME AWS A5.18 ER70S-6 EM MANUTENÇÃO DE PEÇAS DE AÇO AISI 4140
}

\section{EVALUATION OF WELDING WIRE AWS 5.18 MAG USING THE ER70S-6 IN MAINTENANCE OF AISI 4140 STEEL PARTS}

\section{H. A. HOLZMANN ${ }^{1 *}$, J. V. B. RAZENTE ${ }^{2}$ and R. V. B. BISCAIA ${ }^{3}$}

1 Federal University of Technology ï Paraná (UTFPR), Department of Industrial Maintenance Technology, Guarapuava, Paraná, Brazil

${ }^{2}$ Federal University of Technology ï Paraná (UTFPR), Guarapuava, Paraná, Brazil

${ }^{3}$ Federal University of Technology ï Paraná (UTFPR Department of Industrial Maintenance Technology, Guarapuava, Paraná, Brazil

${ }^{*}$ Corresponding author. Universidade Tecnológica Federal do Paraná, Departamento de Tecnologia em Manutenção Industrial, Guarapuava, Paraná, Brasil, Phone: +55 42 99926-1998

e-mail addressl: haholzmann@utfpr.edu.br (H. A. Holzmann).

\begin{tabular}{l} 
A R T I C L E I N F O \\
\hline Article history: \\
Received 2020-06-23 \\
Accepted 2020-09-04 \\
Available online 2020-09-04 \\
p a l a vr a s-ch a ve \\
Aço SAE 4140 \\
Manutenção \\
Soldagem MIG \\
Parâmetros de Soldagem \\
$k$ e y wo r $d s$ \\
Steel AISI 4140 \\
Maintenance \\
Welding MAG \\
Welding Parameters.
\end{tabular}

As a result of the growing technological advance and contribution to market demand and current technological development, the study and application of steel focused on developing different mechanical and structural properties has become important for the industrial branch. In this context, welding is present. Therefore, the objective of this work is to evaluate the weld bead in the MAG welding process using AWS A5.18 ER70S-6 wire deposited in SAE 4140 steel, selecting welding parameters that are closer to the restoration of the original condition of the steel base metal. For this, the cut and the preparation of 5 samples welded by the MAG welding process were performed, in which the welding current and voltage parameters were varied with constant welding speed. In which the hardness measurements of the samples were performed and then the inlay followed by microstructural analysis. The results obtained with the analyzes were concrete due to the hardness obtained, however, the martensitic index increased due to the high cooling rate, allowing the embrittlement of the material and limiting its applicability

\section{R E S UM O}

Em decorrência do avanço tecnológico crescente e para a contribuição com a demanda de mercado e desenvolvimento tecnológico atual, o estudo e aplicação do aço focados em desenvolver diferentes propriedades mecânicas e estrutural se tornou importante para o ramo industrial. Nesse contexto, a soldagem se faz presente. Portanto, este trabalho tem por objetivo avaliar o cordão de solda no processo de soldagem MAG utilizando arame AWS A5.18 ER70S-6 depositado em aço AISI 4140, selecionando parâmetros de soldagem que mais aproximam a restauração da condição original do metal base do aço. Para tal, foi realizado o corte e a preparação de 5 amostras soldadas pelo processo MAG de soldagem, na qual variou-se os parâmetros de corrente e tensão de soldagem com velocidade de solda constante. No qual foi realizado repetições de medição de dureza das amostras e então o embutimento seguido por análise microestrutural. Os resultados obtidos com as análises realizadas foram concretos perante a dureza obtida, todavia ocorreu o aumento do índice martensítico devido elevada taxa de resfriamento, possibilitando a fragilização do material e limitando sua aplicabilidade 


\section{INTRODUÇ̃̃̃O}

Em decorrência do grande avanço tecnológico das últimas décadas, diversos segmentos industriais buscaram desenvolver-se, para se manterem estáveis no mercado industrial. Buscando contribuir com a demanda de mercado e o desenvolvimento tecnológico, o estudo e aplicação de aços focados em desenvolver diferentes propriedades mecânicas, principalmente no quesito de soldabilidade, se tornou ponto chave para indústrias de fabricação.

No ramo da manutenção industrial, o objetivo é manter a alta disponibilidade do maquinário. Dessa forma, uma das maiores dificuldades está no reparo das falhas que incapacitam o processo produtivo. Para Krella e CzyŨhiewski (2006), as falhas por fraturas resultam da propagação de trincas no material. Estas ocorrem devido a solicitações de trabalho acima do suportado ou devido a fadiga. Já as falhas por desgaste podem ser geradas devido a abrasão, adesão, ớrettingô cavitação, erosão e fadiga (NEALE E GEE, 2001).

As falhas por desgaste são fatores que influenciam diretamente no custo da manutenção e produção de uma empresa, impactando diretamente no funcionamento do maquinário em consequência de ocorrências de falha, ocasionando a interrupção do processo produtivo (GREGOLIN, 1990).

Para garantir a disponibilidade do maquinário e minimizar as perdas devido as horas de máquina parada, ações corretivas de manutenção são necessárias. Dentre elas, a soldagem de componentes mecânicos. O processo de soldagem na manutenção visa reparar o maquinário rapidamente, mantendo o mesmo padrão de funcionamento, objetivando prolongar a vida útil dos componentes mecânicos, aumentar a disponibilidade do maquinário e minimizar os custos de manutenção (MARQUES, 2010). O reparo dessas falhas é essencial para o programa de manutenção, visto que tem por uma de suas funções prolongar a vida útil de materiais.
(DUTRA, 2005; GOUVEIA, 2008; BENTO, 2011).

Existem duas importantes aplicações dos processos de soldagem no meio industrial, são elas o processo de soldagem aplicado à produção e o processo de soldagem aplicado à manutenção. Enquanto a soldagem de produção é feita em ambientes controlados, utilizando corpos de provas, com equipamentos apropriados e conhecimento da composição química do metal base, a soldagem de manutenção, por sua vez, é realizada em casos de extrema necessidade devido as falhas. Dessa forma, existem limitações de trabalho para esse tipo de aplicação, devido principalmente à rapidez com que o processo deve ser feito para repor o equipamento ao processo produtivo da indústria (MOBLEY, 1997).

Nos processos de soldagem a qualidade do depósito caracteriza-se como um ponto crítico na rotina das indústrias, tanto pelo acúmulo de porosidades no material, quanto pela microestrutura gerada na região. Buscando-se um controle rígido deve-se realizar algumas etapas, a fim de garantir a qualidade da solda, como mostrado na Figura 1 (DUTRA, 2005; GOUVEIA, 2008; MARQUES, 2004).

Dutra (2005) e Gouveia (2008) enfatizam que a qualificação do procedimento de soldagem é um ponto crítico no trabalho de indústrias, principalmente devido a qualidade do deposito da solda, a qual é influenciada pelo aparecimento de porosidades. Dessa forma, se faz necessário rigorosos critérios durante o processo de soldagem devido as condições em que os materiais deficientes se encontram, tais como a determinação dos materiais a serem utilizados, o TTR (tempo para reparo) limite perante o custo de máquina parada, a preparação da área afetada e o procedimento de soldagem (intensidade da corrente elétrica do arco, velocidade da solda, dentre outros), para esse tipo de solda geralmente é utilizado o processo MIG/MAG.

$\mathrm{O}$ processo de soldagem MIG/MAG é empregado principalmente devido à alta taxa de deposição, capacidade de soldagem em diversos tipos de materiais (TEIXEIRA, 2011).

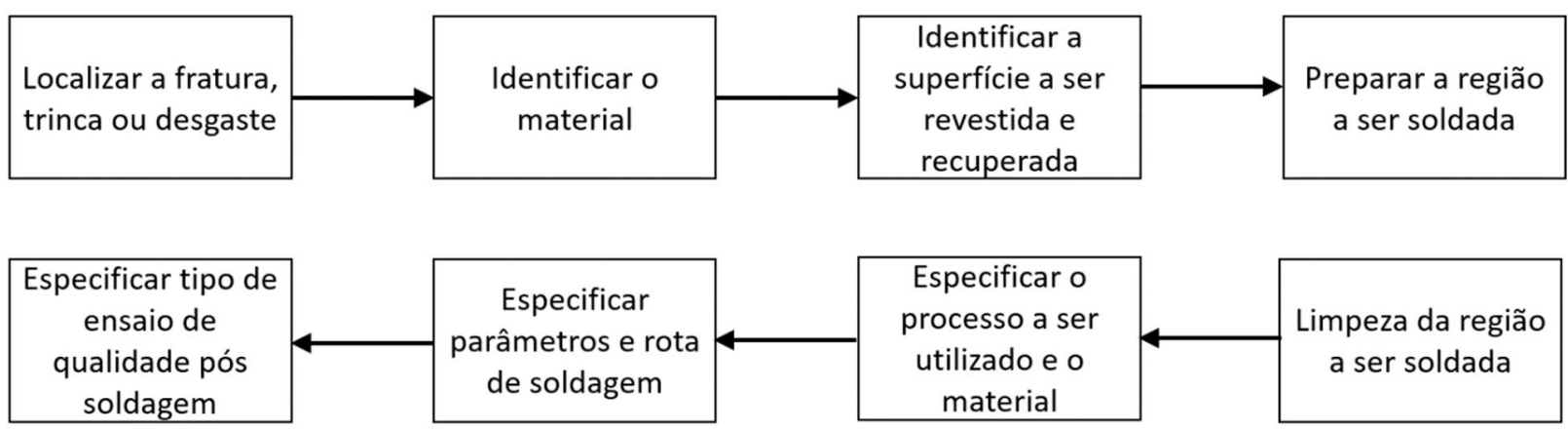

Figura 1 - Etapas a serem seguidas na soldagem de manutenção. Fonte: Adaptado de Marques (2010).

Com a solda de recuperação realizada, deve-se verificar o cordão obtido, bem como a região afetada pelo processo. Para Forte (2005), a região da solda apresenta uma zona termicamente afetada, a qual compreende o local em que regiões da solda não se fundiram durante o processo de soldagem, mas a microestrutura e as propriedades térmicas, químicas e físicas podem ter sido alteradas devido ao calor gerado pela soldagem. Forte (2005) ainda afirma que, por possuir menor resistência, a região da zona termicamente afetada pode comprometer a resistência de uma junta soldada.
Desta forma a composição química tanto do metal base como do arame de solda são de extrema importância, visando obter características mecânicas suficiente para um pleno funcionamento do equipamento.

Portanto, se faz necessário analisar as características obtidas através de variações nos parâmetros de soldagem, visando garantir melhores resultados no TTR (Time to Repair), possibilitando atender aos requisitos de disponibilidade, aliados com diminuição de custos e com o aumento de produtividade. Com o presente trabalho buscou-se avaliar o cordão de solda no 
processo de soldagem MAG utilizando arame AWS A5.18 ER70S-6 depositado em aço AISI 4140.

O aço AISI 4140 é um aço de baixa liga, ao cromo e molibidenio, com elevada resistência, podendo ser utilizado em temperaturas próximas a $480^{\circ} \mathrm{C}$, altamente susceptível a tratamentos térmicos. Além disso, apresenta boa resistência à torção e à fadiga, e a dureza na condição temperada varia de 54 a 59HRC (ROCHA, 2004).

\section{METODOLOGIA}

O desenvolvimento do projeto se deu por meio da avaliação do cordão de solda no processo de soldagem MAG utilizando arame AWS A5.18 ER70S-6 depositado em aço AISI 4140, composição química descria na Tabela 1 (GERDAU, 2018).
Já o arame utilizado, é uma denominação comercial, sendo de fácil acesso e de extremo controle de cordão e microestrutura gerada. Apresenta características de resistência próximas ao aço AISI 4140, mas com menos resistência a médias temperaturas e a ambientes agressivos.

Desta forma para alcançar o objetivo, fez-se necessário realizar os ensaios de soldagem MAG com variação dos parâmetros de corrente e tensão para o aço AISI 4140, analisar o perfil de dureza e a micrografia das amostras.

Para isso, foi realizado o corte da barra de aço SAE 4140 (com uma dureza de $92 \mathrm{HRB}$ ) e dividida em 05 partes iguais, constituindo $20 \mathrm{~mm}$ de espessura; $50 \mathrm{~mm}$ de comprimento e 30 $\mathrm{mm}$ de largura.

Tabela 1 - Composição química do metal base e do arame de solda.

\begin{tabular}{|c|c|c|c|c|c|c|c|c|c|c|}
\hline & \multicolumn{10}{|c|}{ Análise Química (\%) } \\
\hline & C & Mn & Si & $\mathbf{P}$ & $\mathbf{S}$ & $\mathbf{N i}$ & $\mathbf{C r}$ & Mo & $\mathbf{V}$ & $\mathbf{C u}$ \\
\hline AISI 4140 & $0,38-0,43$ & $0,75-1,00$ & $0,15-0,30$ & $\begin{array}{l}0,035 \\
\text { (máx) }\end{array}$ & $\begin{array}{c}0,04 \\
\text { (máx) }\end{array}$ & - & $0,80-1,10$ & $0,15-0,25$ & - & - \\
\hline ER70S-6 & $0,06-0,15$ & $1,4-1,85$ & $0,8-1,15$ & 0,025 & 0,035 & 0,15 & 0,15 & 0,15 & 0,03 & 0,5 \\
\hline
\end{tabular}

As amostras foram soldadas pelo processo de soldagem MAG (Metal Active Gas), utilizado a Máquina de Soldagem MIG/MAG SUMIG, modelo Hank 335, Figura 2. O arame utilizado no processo foi o arame de classe AWS A5.18, tipo ER70S-6. Foram realizadas cinco amostras utilizando os parâmetros de soldagem contidos na Tabela 2, ressalta-se que a soldagem foi feita com auxílio de um sistema de movimentação automática da tocha de soldagem, marca Bug'O, com capacidade de movimentação em dois eixos (eixo $\mathrm{X}$ e $\mathrm{Y}$ ), mantendo constante a velocidade de soldagem, o gás utilizado nos experimentos foi uma mistura de $75 \%$ Argônio + 25\% CO2 (SOUZA, 2011).

Após a soldagem, as amostras foram resfriadas a temperatura ambiente, e na sequencia cortadas a fim de se expor a secção do perfil da amostra, conforme Figura 3. Nesta etapa foram realizadas as análises de macro dureza, utilizando o Durômetro Mecânico Digimess com edentador esférico de 1/16" e pré-carga de 150 kgf, por meio do gradiente de dureza. Foram definidos os pontos para a medição com espaçamento de $3 \mathrm{~mm}$ a partir do cordão de solda e 10 medições de dureza em cada um dos pontos, na sequência realizou-se o cálculo de desvio padrão.

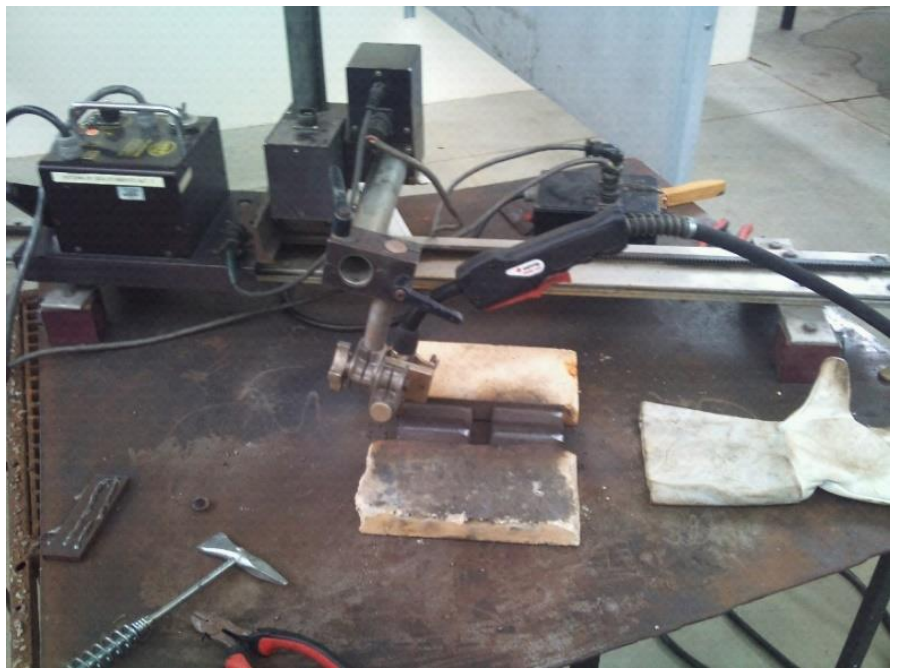

Figura 2 - Sistema de soldagem das amostras.

Tabela 2 - Parâmetros de soldagem utilizados na soldagem.

\begin{tabular}{cccccc} 
Amostra & Corrente (A) & Tensão (V) & $\begin{array}{c}\text { Velocidade de } \\
\text { soldagem (mm/s) }\end{array}$ & $\begin{array}{c}\text { Velocidade de alimentação do } \\
\text { arame de solda (m/min) }\end{array}$ & $\begin{array}{c}\text { Vazão do gás de } \\
\text { proteção (L/min) }\end{array}$ \\
\hline $\mathbf{1}$ & $100-125$ & $15-16$ & 25 & 5 & 10 \\
$\mathbf{2}$ & $125-150$ & $17-18$ & 25 & 5 & 10 \\
$\mathbf{3}$ & $150-175$ & $18-20$ & 25 & 5 & 10 \\
$\mathbf{4}$ & $175-190$ & $22-25$ & 25 & 5 & 10 \\
$\mathbf{5}$ & $190-205$ & $25-28$ & 25 & 5 & 10 \\
\hline
\end{tabular}

Para caráter comparativo, o ponto inicial da comparação inicia-se a partir da linha base das amostras, possibilitando a comparação dos resultados de acordo com a variação dos parâmetros de soldagem nas diferentes amostras. As marcações são evidenciadas na Figura 3.

Na sequência realizou-se o embutimento das amostras, as quais foram lixadas e polidas, para destacar os contornos de 
grão e as estruturas do metal, realizou-se um ataque químico com reagente Nital a $10 \%$, com tempo de ataque de 5 segundos.

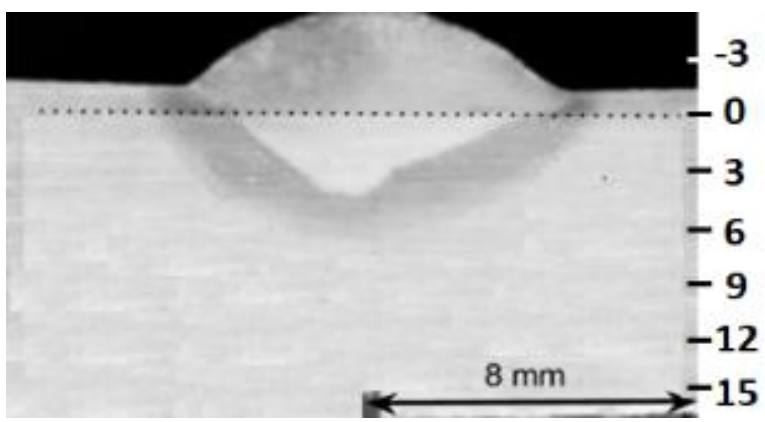

Figura 3 - Pontos de interesse para ensaio de dureza.

Após esta etapa as amostras foram levadas ao microscópio óptico marca Olympus modelo BX521, para visualização do cordão de solda foram obtidas imagens com 1x. $\mathrm{Na}$ avaliação do cordão de solda e ZTA, deve-se identificar as principais informações geométricas, contidas na Figura 4, que permitem verificar se a junta de solda foi adequadamente preenchida com o mínimo de defeitos (PESSOA ET AL., 2010).

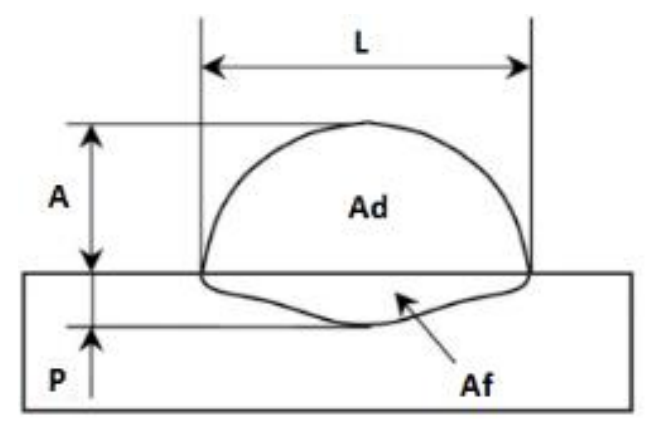

Figura 4 - Perfil geométrico de um cordão de solda

Sendo L a largura do cordão, A a altura do cordão, $\mathrm{P}$ a penetração do cordão, Ad a área depositada e Af área fundida. Através do perfil geométrico do cordão de solda obtém-se a altura, largura e penetração, as quais são influenciadas de acordo com os parâmetros de soldagem utilizados, afetando diretamente na taxa de deposição, no reforço e na diluição do material de adição, está definida pela Equação 1, nesse processo foi utilizado o Software AutoCAD como auxilio a obtenção das medidas (MARQUES, MODENESI E BRACARENSE, 2009).

Para análise do perfil geométrico das amostras, fez-se necessário determinar largura, altura e penetração do cordão de solda, assim como a área de fusão do metal base e a área depositada do cordão, através da Equação 1.

$$
D=\frac{A f}{A d+A f}
$$

Na sequência através do microscópio óptico, as amostras foram analisadas com uma ampliação de 20x, a fim de verificar a microestrutura das amostras, diferenciando-as em metal base (MB), cordão de solda (CS) e interface de solda (IS).

Por fim os cordões de solda foram comparados, verificando a viabilidade do uso do arame de solda AWS A5.18, tipo ER70S-6 na manutenção de peças de aço AISI 4140.

\section{RESULTADOS E DISCUSSÃO}

De acordo com a variação dos parâmetros de soldagem adotados, foram obtidos cordões de solda com diferentes características. Dessa forma, as dimensões do cordão de solda de cada amostra, assim como a diluição (D) encontram-se na Tabela 3.

Os cálculos da diluição dos cordões de solda foram baseados seguindo a Equação 1. Nota-se que todas as medidas obtidas, foram tomadas utilizando o Software AutoCAD, no modo de medição de linhas e de áreas.

Tabela 3 - Características da área soldada.

\begin{tabular}{cccccccc} 
Amostra & ZTA $(\mathbf{m m})$ & $\mathbf{L}(\mathbf{m m})$ & $\mathbf{A}(\mathbf{m m})$ & $\mathbf{P}(\mathbf{m m})$ & $\mathbf{A d}\left(\mathbf{m m}^{\mathbf{2}}\right)$ & $\mathbf{A f}\left(\mathbf{m m}^{\mathbf{2}}\right)$ & $\mathbf{D}$ \\
$\mathbf{1}$ & 2,01 & 8,023 & 5,750 & 0,993 & 39,559 & 4,599 & 0,104 \\
$\mathbf{2}$ & 2,34 & 10,649 & 2,110 & 2,823 & 17,037 & 22,717 & 0,571 \\
$\mathbf{3}$ & 2,85 & 9,425 & 2,605 & 5,339 & 21,793 & 32,794 & 0,601 \\
$\mathbf{4}$ & 3,23 & 8,588 & 1,525 & 2,330 & 10,068 & 15,376 & 0,604 \\
$\mathbf{5}$ & 3,56 & 7,248 & 2,357 & 3,436 & 5,281 & 18,946 & 0,782 \\
\hline
\end{tabular}

É possível observar na Tabela 3 que tanto a ZTA quanto a diluição aumentam em decorrência do aumento dos parâmetros de tensão e corrente de soldagem. O aumento da diluição se deve ao aumento da corrente e tensão de soldagem na qual influencia o aporte térmico na região soldada e por consequência altera a disposição da área fundida, uma vez que ao diminuir a velocidade de soldagem aumenta-se o aporte térmico e a penetração da solda (SILVA, 2010).

Os ensaios de dureza foram realizados após procedimento de soldagem e corte, visando verificar as variações ocasionadas pelo processo de soldagem no material. Foi realizado gráfico do perfil de dureza para cada amostra, diferenciando-as pela escolha do parâmetro utilizado no procedimento de soldagem. Os resultados podem ser observados na Figura 5.

É possível observar na Figura 5 que a dureza média da amostra 1 está abaixo da dureza padrão original do metal base, $92 \mathrm{HRB}$, atingindo valores próximos de 86,5 de dureza Rockwell B. Uma das explicações do resultado de dureza é a possível diminuição do gradiente térmico durante o processo de solda. Esse resultado é razão da baixa de corrente de soldagem, se comparado as outras amostras, afetando a penetração do cordão de solda e a diluição do metal de adição. Após a linha base indicada previamente como linha 0 , nota-se que ocorreu uma elevação dureza devido a menor influência da temperatura, resultando em uma dureza próxima a original do metal base.

Já para a amostra 2, percebe-se patamares maiores de 
dureza se comparadas a primeira amostra, visto que ocorreu uma maior penetração do material de adição e uma maior influência da temperatura, aumentando a extensão da ZTA, o que gera uma diminuição da dureza próximo a marcação dos 6 milímetros, isto se dá devido à maior quantidade de energia disponível para recristalização da estrutura, resultando em grãos maiores na região.

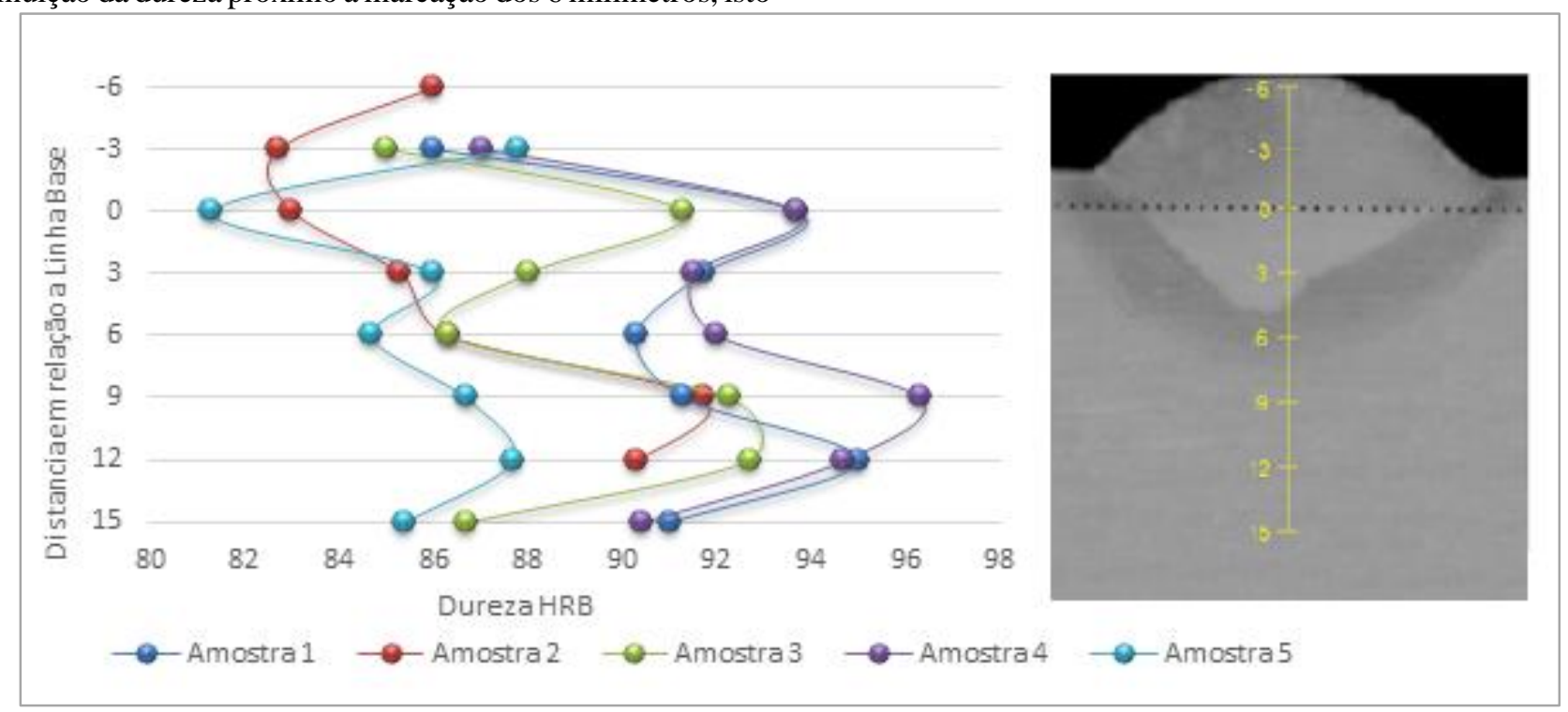

Figura 5 - Perfil de dureza das amostras.

$\mathrm{Na}$ amostra 3 observa-se um mesmo padrão da curva de dureza da amostra 2, apenas com uma elevação de 2 pontos percentuais de dureza, sendo resultado de uma maior corrente de soldagem, a qual fornece um maior aporte térmico e por consequência uma maior profundidade de penetração do metal de adição e uma ZTA mais abrangente, até aproximadamente 9 milímetros.

$\mathrm{Na}$ amostra 4, devido a maior corrente de soldagem, ocorre uma alteração na forma do cordão de solda, devido ao calor gerado no processo, possibilitando alteração no crescimento dos grãos, taxa de resfriamento e maior aparecimento de discordâncias, explicação essa que corrobora com Forte (2005).

Para a amostra 5 observa-se um perfil de dureza com valores mais baixos que as demais amostras. Isso ocorre devido ao aumento de fusão de materiais e permanência em temperaturas elevadas durante um maior tempo, findando em maior tempo para resfriar a parte mais externa do cordão de solda.

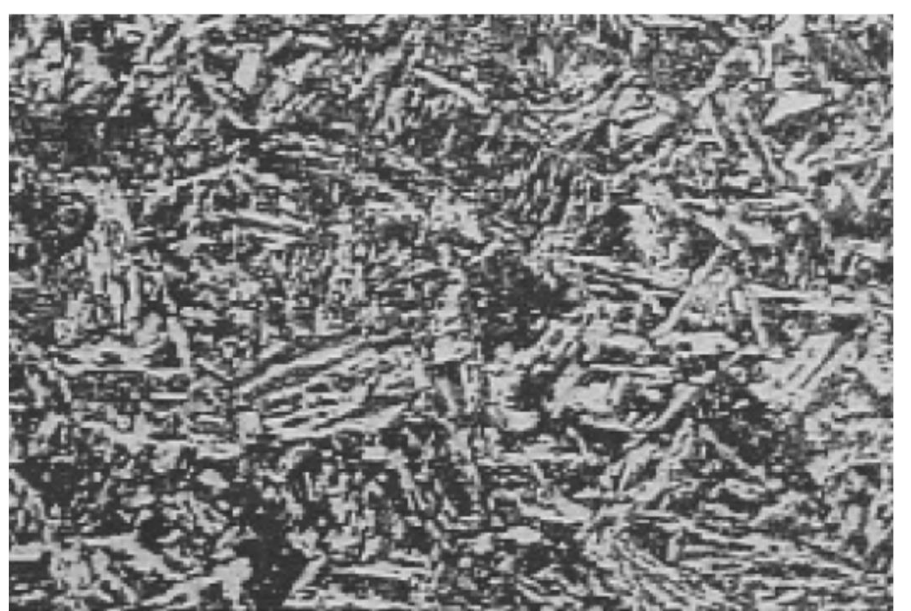

Figura 6 - Microestrutura aço AISI $4140 \mathrm{com}$ aumento de 100x.

Fonte: Pannoni e Pinedo (2006).
Quanto a análise microestural do metal de base e do cordão de solda pode-se perceber que em todas as amostras observa-se uma formação de microestrutura característica de um aço hipoeutetóide martensitico, possuindo regiões escuras de perlita (parte mais clara) em matriz ferrítica (parte mais escura), em seu metal base original, apresentado na Figura 6, variando a profundidade do aparecimento da microestutura tipica do aço AISI 4140, devido ao aporte térmico gerado em cada um dos parâmetros de processo.

Percebe-se através da Figura 7, em ampliação de 100x, que a microestrutura do cordão de solda apresentou uma formação com características do material de adição (AWS A5.18 ER70S-6) composta basicamente por ferrita e perlita, porém, devido a influência da amplitude térmica de soldagem, ele ainda se encontra no estado bruto de fusão, apresentando granulação grosseira devido ao superaquecimento, sendo visível em todas as amostras efetuadas (COLPAERT, 2008).

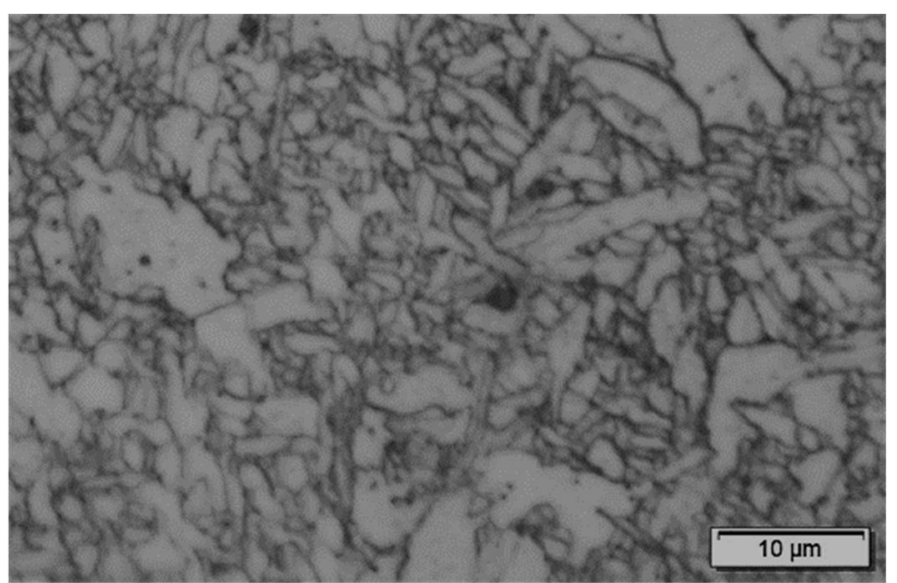

Figura 7 - Microestrutura do cordão de solda - metal de adição.

Na Figura 8 nota-se a formação martensitica nas regiões de alta dureza, em função do alto teor de carbono existente na estrutura cristalina do aço e pelas altas velocidades de resfriamento. O metal de solda é formado por regiões 
dendríticas, com composição heterogênea, sendo que a microestrutura se apresenta mais grosseira no cordão de solda, que na própria ZTA e metal base (SILVA, 2010).

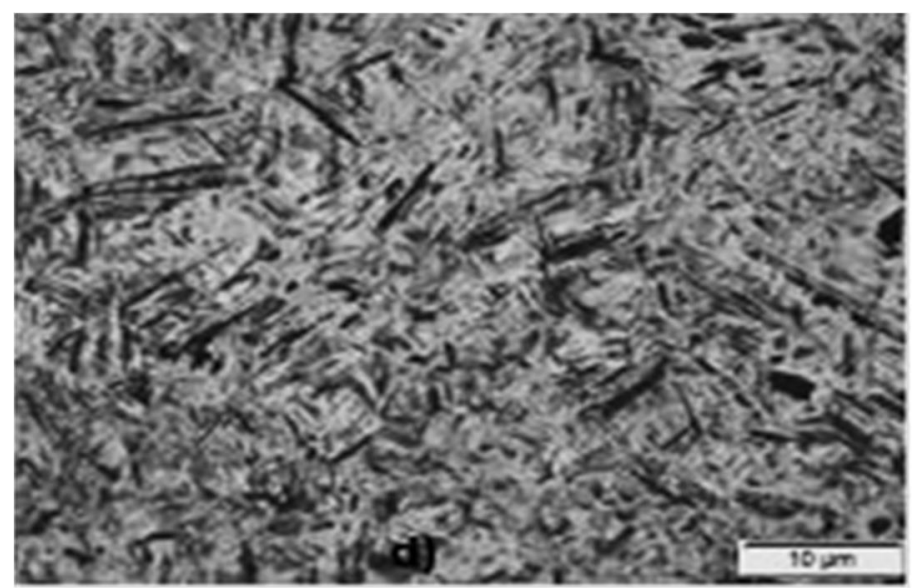

Figura 8 - Microestrutura do cordão de solda - metal base.

Pode-se observar no início da ZTA, a presença de grãos colunares de perlita, ferrita de contorno de grão e ferrita acicular (ripas claras), juntamente com a formação austenítica próxima a ZTA.

Utilizando as informações do ensaio de dureza, observase que a menor dureza média foi causada pela combinação de maior corrente e tensão escolhido. Isso ocorreu devido maior tempo de permanência da amostra em temperaturas elevadas, ocasionando menores taxas de resfriamento, possibilitando na queda significativa de dureza geral.

Para Silva (2010), o resfriamento do cordão de solda é mais abrupto na superfície e mais lento na parte central do cordão, originando aumento de dureza, resistência ao desgaste e tração, causando uma diminuição da ductilidade e aumento da fragilidade do material.

Verificou-se portanto que os parâmetros de soldagem indicados para a prática de soldagem MAG de manutenção em aços AISI 4140 utilizando arame AWS A5.18 ER70S-6 estão na faixa utilizada nas amostras 3 e 4 . Isso se deve ao fato de que foi obtida dureza similar ao metal base, na região fundida.

\section{CONCLUSÃO}

Com base nas análises realizadas e resultados obtidos, pode-se concluir que:

O aumento dos parâmetros tensão e corrente de soldagem no processo de soldagem MIG, possibilitou o aumento no índice de diluição das amostras. Esse aumento por sua vez, influi no aporte térmico da soldagem o qual impacta diretamente na penetração da solda e na disposição da área fundida.

Os aumentos dos parâmetros também propiciaram aumento no perfil médio de dureza nas amostras 1,2,3,4 respectivas. Entretanto, ocorreu uma queda no perfil de dureza da amostra 5 que pode ser explicada devido ao elevado índice de diluição e resfriamento interno mais lento.

Com a análise metalográfica realizada, é possível concluir que ocorreu a formação de martensita nas amostras 1,2,3 e a formação de grãos colunares de perlita, ferrita de contorno de grão e ferrita acicular na amostra 4. Já a amostra 5 apresentou características de formação de austenita retida ao mesmo passo que ocorria a formação de martensita.

Por fim, conclui-se que as amostras 3 e 4 obtiveram os melhores resultados no quesito de restabelecer a condição básica de dureza do material, atingindo dureza media HRB 91,29 e 92,23 respectivamente. Todavia, com o aumento de dureza ocorrido devido maiores formações de martensita em detrimento a elevada taxa de resfriamento, ocorre a fragilização do material, possibilitando a formação de trincas e podendo inviabilizar seu uso em casos que ocorrem inúmeros impactos mecânicos.

\section{R E FER E N C I A S}

ARAMES PARA SOLDA, GERDAU. CATÁLOGO ARAMES PARA SOLDA. Disponível em: <http://www.comercialgerdau.com.br/pt/productsservic es/products/Document\%20Gallery/catalogo-aramespara-solda.pdf $>$. Acesso em: 20 de jun. 2018.

BENTO, Emerson André Pinto; SARNI, Mírian Isabel Junqueira. Melhoria do processo de soldagem da recuperação de eixos de moenda. Ciência \& Tecnologia, v. 3, n. 1, 2011.

COLPAERT, H. Metalografia dos produtos comuns. 4. ed. revista e atualizada. São Paulo: Editora Blucher, 2008.

DUTRA, Jair Carlos. Sistema e processo de soldagem vencendo a erosão das turbinas hidráulicas de grande porte. ENERGIA PARA O MERCOSUL, p. 101, 2005.

FORTE, Cleber. Soldagem MIG / MAG - traduzido e adaptado. Contagem: ESAB, 2005.

GREGOLIN, Jose Angelo Rodrigues et al. Desenvolvimento de ligas Fe-C-Cr-(Nb) resistentes ao desgaste. (Publicação FEC), 1990.

GOUVEIA, Ruimar Rubens. ñA influência da temperatura de interpasse na tenacidade do metal de solda na soldagem multipasse do aço inoxidável martensitico CA6NM pelo processo TIGò. 2008

KRELLA, Alicja; CZY€ NIEWSKI, Andrzej. Cavitation erosion resistance of Crï N coating deposited on stainless steel. Wear, v. 260, n. 11, p. 1324-1332, 2006.

MARQUES, Marcelo Fernando de Sousa. Aplicação da soldagem na manutenção industrial. 2010.

MARQUES, Paulo Villani; MODENESI, Paulo José; BRACARENSE, Alexandre Queiroz. Soldagem: fundamentos e tecnologia. Ed. da UFMG, 2005.

MOBLEY, R. Keith. Maintenance fundamentals: 2 edition. [S.L.]: Butterworth-Heinemann, 2004. 424 p.

NEALE, Michael; GEE, Mark. A guide to wear problems and testing for industry. William Andrew, 2001.

PESSOA, Antonio Rodolfo Paulino et al. Using the Taguchi method to select welding parameters for weld overlay with nickel alloy through the GMAW process. Soldagem \& Inspeção, v. 15, n. 4, p. 317-324, 2010.

ROCHA, M. A. C. et al. Análise das propriedades Mecânicas do aço SAE 4140 com estrutura bifásica. UFF-Universidade 
Federal Fluminense. Niterói-RJ, 2004.

SILVA, Jorge Alexandre Santos Pinheiro da et al. Tratamento térmico de juntas soldadas. 2010.

SOUZA, Daniel et al. Influência da Regulagem de Parâmetros de Soldagem sobre a Estabilidade do Processo MIG/MAG Operando em Curto-Circuito. Revista Soldagem e Inspeção, São Paulo, v. 16, n. 1, p. 022-031,
2011.

TEIXEIRA, Gustavo Simões. Análise da influência dos Parâmetros de Soldagem sobre a geometria do Cordão de Solda depositado pelo processo de Soldagem TIG-MAG em tandem. 2011. 